\title{
Fit for Purpose? 3D Printing and the Implications for Design Law: Opportunities and Challenges
}

\author{
Dinusha Mendis*
}

\section{Introduction}

\begin{abstract}
Enforcement may become even more complex in the future with the emergence of 3D printing. This technology makes it easier to breach industrial designs and hence it is necessary to question exactly how rights will be enforced in the future ... Enforcing infringement laws is likely to become a complicated process with the decentralised nature of $3 \mathrm{D}$ printing counterfeit and piracy... Furthermore, the anonymity and perception of safety that comes along with infringement inside private homes along with the ease and low-cost of $3 \mathrm{D}$ printers contributes to these complications. ${ }^{1}$
\end{abstract}

The above quote captures the challenges presented by additive manufacturing or 3D printing as it is more commonly known. The term 'additive manufacturing' emanates from the process of creating a product layer-by-layer. From an article written in the New Scientist on 3 October $1974^{2}$ outlining the concept, to the first patent granted in 1988 to Charles Hull for the first commercial 3D printer, the technology has come a long way. ${ }^{3}$ Since then, the technology has continued to develop significantly and has led to the creation of various end products in the medical, transport, food, toy and hobby and the fashion and cosmetic industries to name a few. ${ }^{4}$ Whilst this new technology has opened up new frontiers, there is the fear that manufacturing and businesses will be disrupted as regular people gain access to power tools of design and production. ${ }^{5}$

Accordingly, the recent introduction of home-based 3D printing has enabled consumers to engage in the manufacture of products using digital data bought or 'shared' online circumventing much of the traditional manufacturing and retail value chain ${ }^{6}$. In turn, it has

\footnotetext{
*Professor of Intellectual Property \& Innovation Law; Co-Director Centre for Intellectual Property Policy and Management (CIPPM), Bournemouth University

${ }^{1}$ Economic Review of Industrial Design in Europe (MARKT2013/064/D2/ST/OP) (Europe Economics; 2015), p. 13

2 Jones D., 'Ariadne' Column, 3 October 1974, New Scientist, p. 80

${ }^{3}$ Application no. 06/638,905 filed 8 August 1984. U.S. Patent 4,575,330 'Apparatus for Production of Three-Dimensional Objects by Stereolithography' granted 11 March 1986

${ }^{4}$ European Parliament, Working Document on Three- Dimensional Printing, a Challenge in the Fields of Intellectual Property Rights and Civil Liability (23 November 2017)

${ }^{5} \mathrm{H}$ Lipson \& M Kurman, Fabricated: The New World of 3D Printing (Indiana: John Wiley \& Sons, Inc.; 2013), 7

6 Innovate UK, Materials KTN: Shaping Our National Competency in Additive Manufacturing
} (September 2012), p. 4. As a digital technology, 'Additive Manufacturing' (more commonly called 3D 
provided the potential for designing, sharing and reproducing physical objects. At consumerlevel, there is the likelihood of disruption to certain business models as 3D printing is likely to allow much more precise customisation of products. ${ }^{7}$

Whilst, actual infringement of designs through the use of 3D printers remain relatively low at present, due to limitations in technology, access to printing material and the cost of hardware, ${ }^{8}$ many reports and studies ${ }^{9}$ have confirmed concerns surrounding the anticipated impact of such copying. ${ }^{10}$ Moreover, given the decreasing costs in $3 \mathrm{D}$ printers, advancements in technology and greater access to online tools for consumer use, it is reasonable to anticipate that it may become a significant issue in the near future. ${ }^{11}$ Therefore, in adapting to this technology, it is both prudent and timely to review the current design laws in order to adopt policy recommendations before the reproduction of physical objects do what MP3 files did for music and film. ${ }^{12}$

This chapter will commence by setting out a brief introduction to registered and unregistered design rights, from the perspective of the United Kingdom (UK) and influence by the European Union (EU), before moving on to a consideration of the challenges posed by 3D printing. In this context, the chapter will, first, consider the legal status of a Computer-Aided Design (CAD) file within the context of registered and unregistered design, before proceeding to consider the implications presented through infringement and possible exceptions available for users. Highlighting challenges and raising questions on design laws' ability to provide stringent

Printing) is progressively being integrated with the Internet enabling consumers to engage directly in the design process, and allowing true consumer personalisation

7 Economic Review of Industrial Design in Europe (MARKT2013/064/D2/ST/OP) (Europe Economics; 2015), p. 13; see also, European Parliament, Working Document on Three- Dimensional Printing, a Challenge in the Fields of Intellectual Property Rights and Civil Liability (23 November 2017) ${ }^{8}$ Mendis D. and Secchi D., A Legal and Empirical Study of 3D Printing Online Platforms and an Analysis of User Behaviour (London: UK Intellectual Property Office; 2015)

${ }^{9}$ Reeves P. and Mendis D., The Current Status and Impact of 3D Printing Within the Industrial Sector: An Analysis of Six Case Studies (Intellectual Property Office, 2015); Dumotier J et at., Legal Review on Industrial Design Protection in Europe (MARKT2014/083/D) (European Commission; 2016); Economic Review of Industrial Design in Europe (MARKT2013/064/D2/ST/OP) (Europe Economics; 2015); Margoni T., Not for designers: On the Inadequacies of EU Design Law and How to Fix It (2013) 4 Journal of Intellectual Property, Information Technology and E-Commerce Law 225; Malaquias P., Consumer 3D Printing: Is the UK Copyright and Design Law framework fit for purpose? (2016) 6 Queen Mary Journal of Intellectual Property 321

10 ibid, p. 131

${ }^{11}$ Mendis D. Secchi D. and Reeves P., A Legal and Empirical Study into the Intellectual Property Implications of 3D Printing (Intellectual Property Office, 2015). See, https://www.gov.uk/government/publications/3d-printing-research-reports

${ }^{12}$ Mendis D., "The Clone Wars": Episode 1 - The Rise of 3D Printing and its Implications for Intellectual Property Law - Learning Lessons from the Past?' [2013] European Intellectual Property Review 155, pp. 154-155 
enforcement for rights holders, the chapter will outline potential recommendations, drawn from patent and copyright laws, before concluding with some thoughts for the future.

\section{Design Law: A Myriad of Legislation}

Design law which applies in the UK is comprised of four sets of design rights: Community Registered Design Right (CRDR) ${ }^{13}$; Community Unregistered Design Right (CUDR) ${ }^{14}$; UK Registered Design Right (UK RDR) ${ }^{15}$; and UK Unregistered Design Right (UK UDR) ${ }^{16}$. CRDR and CUDR are almost identical in terms of substantive rules, with some disparities such as the term of protection or the scope of infringement. Additionally, Community registered design law is harmonised with the UK registered design law so that the latter is almost identical with the former, whereas UK unregistered design right is not harmonised with Community unregistered design right. As a corollary, CRDR, CUDR, and UK RDR have almost the same rules, except for UK UDR which has considerably different rules from the rest of design rights. Protection provided by these rights could be accumulative and therefore a design could be protected by four different routes. Both CRDR and UK RDR last 5 years, but can be renewed five times, thus the maximum length of protection amounts to 25 years. ${ }^{17}$ In contrast, CUDR only lasts 3 years from the point when the design is first made available to the public ${ }^{18}$, whereas UK UDR lasts up to 10 to 15 years, depending on the point when the design is made available for sale or hire ${ }^{19}$.

With such a myriad of legislation to contend with the next part of this paper will provide an overview of UK registered and unregistered design laws, before considering its application to new technologies such as 3D printing.

\footnotetext{
${ }^{13}$ Council Regulation (EC) No. 6/2002 of 12 December 2001 on Community Designs [2002] OJ L3/1

14 ibid

${ }^{15}$ Registered Design Act 1949 (hereinafter RDA 1949)

${ }^{16}$ Copyright, Designs and Patents Act 1988 (hereinafter CDPA 1988), Part 3

${ }^{17}$ Council Regulation (EC) No. 6/2002 of 12 December 2001 on Community Designs [2002] OJ L3/1, Art 12; RDA 1949, s 8

${ }^{18}$ Council Regulation (EC) No. 6/2002 of 12 December 2001 on Community Designs [2002] OJ L3/1, Art 11(1)

${ }^{19}$ CDPA 1988, s 216(1)
} 


\section{A Brief Introduction to Registered and Unregistered Design in the UK- Influence of EU Law}

\subsection{Registered Design}

The Registered Design Act (RDA) of 1949 has been amended quite significantly, over a period of time and particularly through the Design Directive of 1998 (DD). ${ }^{20}$ The DD was particularly instrumental in bringing UK closer to other Member States, from the perspective of the substantive law. ${ }^{21}$

One of the more interesting elements of RDA 1949 is in relation to the appearance of a product and differs significantly from the definition provided by the Community Design Regulation. ${ }^{22}$ The position in the UK, before 9 December 2001, was that for designs to attract protection it had to appeal to the eye, that is to say it should possess some aesthetic quality. ${ }^{23}$ However, Article 11 of the $D D^{24}$ and its implementation in the UK broadened the definition of designs in the UK and removed the condition of appealing to the eye. ${ }^{25}$ Since then, it is fair to say that UK has a sort of mixed system for pre-December 2001 designs. ${ }^{26}$

Another interesting feature of the RDA since it was updated through the DD, is that it is no longer a requirement for a design to be registered in respect of a specific product. ${ }^{27}$ The implication of this is that any number of new designs can be incorporated into a single application (in contrast to previous UK practice). ${ }^{28}$ Additionally, a declaration to the effect that the owner believes the design is new and has individual character must be signed by the applicants or their representative.

Interestingly, even if all of the above requirements are met, the design can only be protected if it satisfies the vital elements of novelty and individual character, which are paramount for protecting a design. Case law tells us that in defining novelty and individual character, what is

\footnotetext{
${ }^{20}$ Directive 98/71/EC of the European Parliament and of the Council of 13 October 1998 on the legal protection of designs

${ }^{21}$ However, the DD maintained national procedures for obtaining, enforcing and invalidating national registered designs. See also, Vitoria M., et al, Laddie, Prescott \& Vitoria, The Modern Law of

Copyright and Designs, $\left(4^{\text {th }}\right.$ ed) (Butterworths Law; 2011), 1867

${ }^{22}$ Council Regulation (EC) No. 6/2002 of 12 December 2001 on Community Designs [2002] OJ L3/1

${ }^{23}$ Vitoria M., et al, Laddie, Prescott \& Vitoria, The Modern Law of Copyright and Designs, (4 ${ }^{\text {th }}$ ed)

(Butterworths Law; 2011), 1930

${ }^{24}$ Directive 98/71/EC of the European Parliament and of the Council of 13 October 1998 on the legal protection of designs

${ }^{25}$ Vitoria M., et al, Laddie, Prescott \& Vitoria, The Modern Law of Copyright and Designs, $\left(4^{\text {th }} \mathrm{ed}\right)$

(Butterworths Law; 2011), 1888.

26 ibid, 1939 et seq

${ }^{27}$ See also, Bently L. and Sherman B., Intellectual Property Law $\left(4^{\text {th }}\right.$ ed) (Oxford: Oxford University

Press; 2014), p. 696

$28 \mathrm{ibid}, 696$
} 
required most is "clear blue water between the registered design and the prior art", otherwise there is a real risk that design monopolies will or may interfere with routine, ordinary, minor, every-day design modifications - what patent lawyers call "mere workshop modifications." 29 However, in relation to the scope of protection, the standard differs. In other words, it is sufficient to avoid infringement if the accused product is of a design which produces a different overall impression. There is no policy requirement that the difference be "clear." If a design differs, that is enough as long as an informed user can distinguish between the two. ${ }^{30}$

Furthermore, in a field where the requirements for protection are not examined during registration, granting protection to designs that show modest amounts of individual character will contribute to create a system populated by high numbers of untested and potentially poor quality property rights. This could lead to negative consequences on innovation, especially in emerging fields such as that of $3 \mathrm{D}$ printing. ${ }^{31}$

\subsubsection{Unregistered Design}

The background to unregistered design is worthy of note in outlining the current landscape. In the years preceding Copyright, Designs and Patents Act 1988 (CDPA 1988), Vitoria et al explain how copyright law was used as a mechanism to enforce industrial plagiarism. ${ }^{32}$ In particular, copyright in industrial production drawings was used to prevent unauthorised copying of the articles made in accordance with them. ${ }^{33}$ However, copyright's original function was not to protect industrial articles, which, while occasionally possessing artistic elements, often were trivial articles with a functional rather than aesthetic or original nature. ${ }^{34}$ This led to much criticism of copyright being used as a vehicle for protecting creations outside its ambit. On the other hand, it left open the question of the protection for designs that were not registrable (due to the lack of eye appeal, prior to the DD 2001), for which copyright crucially

\footnotetext{
29 Procter \& Gamble Co v. Reckitt Benckiser (UK) Ltd [2007] EWCA Civ 936 [16]-[18]

${ }^{30}$ In this sense, Procter \& Gamble Co v. Reckitt Benckiser (UK) Ltd [2007] EWCA Civ 936 [16]-[18]

${ }^{31}$ See Margoni T., Not for Designers: On the Inadequacies of EU Design Law and How to Fix It (2013) 4 Journal of Intellectual Property, Information Technology and E-Commerce Law 225; see also, Design Rights and 3D Printing in UK: Balancing Innovation and Creativity in a (dis)harmonised and Fragmented Legal Framework in D Mendis et al 3D Printing and Beyond: Intellectual Property and Legal Implications Surrounding 3D Printing and Emerging Technologies (Edward Elgar; 2018) Forthcoming

32 Vitoria M., et al, Laddie, Prescott \& Vitoria, The Modern Law of Copyright and Designs, ( $4^{\text {th }}$ ed)

(Butterworths Law; 2011), especially the case LB (Plastics) $v$ Swish Products [1979] RPC 511, FSR $145(\mathrm{HL})$, therein cited

33 ibid

${ }^{34}$ Vitoria M., et al, Laddie, Prescott \& Vitoria, The Modern Law of Copyright and Designs, $\left(4^{\text {th }}\right.$ ed)

(Butterworths Law; 2011), 1770
} 
became the only form of protection. ${ }^{35}$ At the same time, the type of protection granted by copyright laws could hardly be considered fit for purpose, particularly taking into account the duration of protection; allowing such a long term for functional items, would unduly limit competition and innovation in the industrial field. At the same time, the absence of a registration requirement made copyright very attractive to some industrial sectors, namely those industries where designs change rapidly over time. ${ }^{36}$

It is through these turbulent times that the unregistered right was born through the CDPA 1988 carving out a dedicated design right. Taking inspiration from the - at the time - recently implemented European Directive on the protection of topographies of semiconductor products,${ }^{37}$ the UK legislator introduced a new statutory right for designs called 'design right' (Part III of the CDPA 1988), which, for systematic coherence and terminological clarity, is referred to as UK Unregistered Design Rights (UKUDR).

A design within the meaning of the UKUDR refers to the original design of any aspect of the shape or configuration (whether internal or external) of the whole or part of an article. ${ }^{38}$ Excluded from protection are methods or principles of construction and features of shape which enable the article to be connected to another article (must fit exception) or that are dependent upon the appearance of another article (must match exception). Surface decoration are also excluded from protection as they are usually within the realm of copyright law. ${ }^{39}$

The length of protection granted by a UKUDR is much shorter than its copyright counterpart, reflecting the policy reasons underpinning this right as a form of protection for industrial articles. A UKUDR lasts for a maximum of 15 years (although this is usually much shorter) from when the design was first recorded in a design document or an article was first made to the design, whichever occurs first. ${ }^{40}$ This is still longer than the three years of protection granted by a CUDR thus offering designers an extra tool in the light of the EU unregistered counterpart.

Section 51 of the CDPA 1988 establishes that it is not an infringement of any copyright in a design document to make an article to the design or to copy an article made to the design

\footnotetext{
35 ibid

${ }^{36}$ The balance between protection and competition in the field of designs is outlined, inter alia, by

Davies G., et al Copinger and Skone James on Copyright $17^{\text {th }}$ ed., (London: Sweet \& Maxwell; 2016), $1025-1026$

${ }^{37}$ Council Directive (EC) $87 / 54 / E C$ on the legal protection of topographies of semiconductor products [1986]

${ }^{38}$ CDPA 1988, s $213(2)$

${ }^{39}$ CDPA 1988, s 213(3)(a), (b) and (c); Dyson v Qualtex [2006] EWCA Civ 166, RPC 31

${ }^{40}$ CDPA 1988 s 216 and 237; See also Vitoria M., et al, 1772
} 
(except for artistic works or a typefaces). ${ }^{41}$ Additionally, Section 52 limited the copyright term of protection to 25 years for artistic works exploited by an industrial process producing more than 50 articles, all of which were copies. ${ }^{42}$ The section 52 defence became the object of a lively discussion as the Government promoted its repeal, which was achieved in 2016. ${ }^{43}$ The effect of these sections came to clear light, particularly from a 3D models perspective, in the much discussed Lucasfilm ${ }^{44}$ case (relating to the Star Wars Stormtrooper helmets), where it was held that the helmets were not sculptures and thus could not benefit from the full term of copyright protection, but eventually only from the shorter protection offered by UKUDR, or eventually by the term identified by Sec. 52 . As of 28 July 2016, all artistic works are granted the same length of protection, regardless of whether they were exploited industrially. ${ }^{45}$

Having presented a brief overview of design rights in the UK, the chapter will now turn to consider the challenges posed by 3D printing and its impact for the future of design rights in the UK.

\section{Challenges Posed by 3D Printing}

A commissioned report published in 2016 by the European Commission ${ }^{46}$ concluded that at the most basic level, 3D printing technology can be understood as being a low cost means of easily reproducing objects that could potentially be protected by intellectual property rights, including design rights. ${ }^{47}$ The issue which arises is whether the current legal regime offers a balance between innovation and misappropriation.

On the one hand, it is evidenced that 3D manufacturing occurs in the fashion industries (to produce prototypes and models), and in consumer goods markets to manufacture products such as toys, games, home furnishings and sports equipment. Artists, jewellers and fashion

\footnotetext{
${ }^{41}$ CDPA 1988, s 51(1)

${ }^{42}$ CDPA 1988, s 52. See also Copyright (Industrial Process and Excluded Articles) (No. 2) Order 1989, SI 1989/1070, s 2 and 3. See also Bently L. and Sherman B., n. 27 p. 684

${ }^{43}$ For a detailed and critical account, Bently L., Return to Industrial Copyright? [2012] 34(10) European Intellectual Property Review, pp. 654-672; For details on the legislative history of this amendment see https://www.gov.uk/government/publications/copyright-protection-of-industriallymanufactured-artistic-works

${ }^{44}$ Lucasfilm Ltd \& Others $v$ Ainsworth and Another [2011] 3 WLR 487

${ }^{45} \mathrm{https}$ ://www.gov.uk/government/consultations/transitional-arrangements-for-the-repeal-of-section52-cdpa See also, Mendis D., et al, The Co-Existence of Copyright and Patent Laws to Protect Innovation - A Case Study of 3D Printing in UK and Australian Law in Brownsword R., et al, The Oxford Handbook of Law, Regulation and Technology (Oxford: Oxford University Press; 2017), chapter 19

${ }^{46}$ Dumotier J., et al., Legal Review on Industrial Design Protection in Europe (MARKT2014/083/D) (European Commission; 2016)

47 In relation to the challenges and opportunities presented by 3D printing in the EU region, see Opinion of the European Economic and Social Committee on Living tomorrow. 3D Printing - A Tool to Empower the European Economy, CCMI/131 - Additive Manufacturing, Brussels, 28 May 2015
} 
designers are also deploying the technology in a range of ways to produce one off bespoke pieces. ${ }^{48}$ Moreover, with affordable 3D printers and the emergence of online sharing platforms dedicated to sharing 3D designs, it is possible for individual creators and consumers to share ideas and designs or have their own creation produced. ${ }^{49}$

The 2016 report also established that in the context of 3D printing and industrial designs, the most affected will be that of spare parts. ${ }^{50}$ Interestingly, a commissioned report for the UK Intellectual Property Office (UKIPO), authored by Reeves and Mendis and published in 2015, shed further light on the point of spare parts. The report established that it is possible that parts such as bumpers may one day be produced, in whole or in part using Additive Manufacturing (AM) technologies, but due to the safety of both passengers and pedestrians, the report concluded that this may not happen for a while. ${ }^{51}$ The report, also went to say that it is completely conceivable that component parts for systems such as exterior headlight casings could be made using current or near future AM technologies. ${ }^{52}$

As such, the Studies carried out at both UK and EU level, reveal the challenges which lie ahead for design law as a result of 3D printing. In exploring policy considerations, the next part of this paper, will identify issues pertaining to protection of rights holders, potential exceptions for users, challenges for service providers before concluding with a consideration of the enforcement of design law, in the context of $3 \mathrm{D}$ printing.

\section{Computer Aided-Design (CAD) Files and Design Rights: Eligibility and Protection}

A design in the context of the Community registered and unregistered rights as well as in the context of UK registered design rights means 'the appearance of the whole or a part of a product resulting from the features of, in particular, the lines, contours, colours, shape, texture or materials of the product or its ornamentation,53. The product can be any industrial or

\footnotetext{
${ }^{48}$ AM Platform, Additive Manufacturing: Strategic Research Agenda (2014) at p. 30, available at http://www.rm-platform.com/linkdoc/AM\%20SRA\%20-\%20February\%202014.pdf For a discussion on copyright law, see Rideout B., Printing the Impossible Triangle: The Copyright Implications of Three-Dimensional Printing, (2012) 5 Journal of Business Entrepreneurship \& Law, p. 161, 163-64; Dasari H., Assessing Copyright Protection and Infringement Issues Involved with 3D Printing and Scanning, (2013) 41 AIPLA Q.J. 279; Lee E., Digital Originality, (2012) 14 Vanderbilt. Journal of Entertainment \& Technology Law 919; Weinberg M., What's the Deal with copyright and 3D printing? public knowledge, (Public Knowledge; 2013); Osborn L., Of PhDs, Pirates, and the Public: ThreeDimensional Printing Technology and the Arts, 1 TEX

49 Mendis D. and Secchi D., A Legal and Empirical Study of 3D Printing Online Platforms and an Analysis of User Behaviour (London: UK Intellectual Property Office; 2015);

${ }^{50}$ Dumotier J., et at., Legal Review on Industrial Design Protection in Europe (MARKT2014/083/D) (European Commission; 2016), p. 117

${ }^{51}$ Reeves P. and Mendis D., The Current Status and Impact of 3D Printing Within the Industrial Sector: An Analysis of Six Case Studies (Intellectual Property Office, 2015), p. 19 (based on interviews carried out with stakeholders in the automotive industry)

52 ibid

${ }^{53}$ RDA 1949, s 1(2)
} 
handicraft item and includes packaging, get-up, graphic symbols, typographic type-faces and parts intended to be assembled into a complex product. ${ }^{54}$ Within the ambit of this definition, it should be noted that a computer program does not fall within the meaning of a product. ${ }^{55}$

In order for a design to be successfully registered, the design must be (a) new and (b) have individual character. ${ }^{56}$ 'Novelty' means that a new design should not be identical to another design and the difference between an existing design and the 'new' design should differ more than in immaterial details on what is made available to the public before the relevant date. ${ }^{57}$ The assessment of the second criteria of 'individual character' is determined by applying the test of the 'informed user' by querying whether the overall impression of the new design conjures up other designs which have been made available to the public before the relevant date in the mind of the informed user. Where the design's overall impression differs, the design will attract individual character. ${ }^{58}$

It could be argued that the appearance of a 3D-printed object, including its colours, shapes or texture, is a protectable design, if the above-mentioned substantive requirements can be met. Yet, an unanswered question is whether a CAD file embodying the appearance of the 3Dobject is also protectable. The rationale for posing this question is two-fold: (a) CAD file is an important vessel for carrying the information of an object that is intended to be fabricated and (b) by reproducing or disseminating it, one could potentially facilitate infringement when it is realised into a physical object. ${ }^{59}$

Margoni and Elam, in their respective articles argue that the scope of a product, within the context of design law, can encompass not only a physical, but also a digital product. In this context, they argue that a design generated by a CAD program should be protectable as a design in the same manner as graphic symbols, such as computer icons or graphic user interfaces (GUI). ${ }^{60}$

\footnotetext{
${ }^{54}$ RDA 1949, s $1(3)$

${ }^{55}$ RDA 1949, s $1(3)$

${ }^{56}$ RDA 1949, s 1B (1)

${ }^{57}$ RDA 1949, s $1 B(2)$

${ }^{5}$ RDA 1949, s 1B (3); for the meaning of overall impression, see Procter \& Gamble Co $v$ Reckitt Benckiser (UK) Ltd [2007] EWCA Civ 938; [2008] FSR 8, [23]-[25] (the overall impression stated herein means 'what strikes the mind of the informed user when [the product in question] is carefully viewed'), and for how to assess whether overall impression is immaterially different, see Dyson Ltd $v$ Vax Ltd [2010] EWHC 1923 (Pat); [2011] Business Law Review 232, [37]

${ }^{59}$ RDA 1949, s 7(2) (It is infringement of registered design rights, inter alia, to make a product in which a design is incorporated or to which it is applied.)

${ }^{60}$ Margoni T., Not for Designers: On the Inadequacies of EU Design Law and How to Fix It (2013) 4 Journal of Intellectual Property, Information Technology and E-Commerce Law 225; Elam V., CAD
} 
However, it can be questioned whether a CAD file embodying a physical product (emphasis added) can be seen in the same light as computer icons or GUIs. In relation to the registrabillity of computer icons, Jacob $\mathrm{J}$ in Apple Computer v Design Registry ${ }^{61}$ agreed with the notion that GUls do not fall within the meaning of an 'article' under the old RDA 1949, which was not harmonised under EU design regulation at the time of the decision. However, Jacob $\mathrm{J}$ noted that a computer icon is protectable as a design insofar as it is inherently built into a machine, so as to form part of an article (emphasis added). ${ }^{62}$ The reasoning implies that graphic symbols are protected on the basis that they could be 'the appearance' of a product rather than being considered as 'a product' itself. Accordingly, it is submitted that a more accurate view of designs generated by a CAD program consistent with the wording in RDA 1949, includes digital designs displayed on any computer interface, which eventually form the appearance of a product (emphasis added).

This is so because a CAD file does not function like a computer icon or GUI, as CAD files do not presuppose to be a part of the appearance of an end-product; instead, CAD files contain instructions or act as a blueprint to produce physical objects. Therefore, contrary to the argument presented by Margoni and Elam, a design generated by a CAD program cannot be protected as a design in the same manner as graphic symbols, such as computer icons or GUls. ${ }^{63}$

This argument leads to a corresponding question: if a CAD-based model cannot be deemed a design, in the manner in which computer icons or GUls are protected, what rights do design rights holders have when their CAD-based designs are copied and disseminated, thereby giving rise to potential infringement? Past case law from copyright law, reveals the possibility of protecting blueprints for a three-dimensional industrial articles, ${ }^{64}$ which design rights holders

Files and European Design Law (2016) 7 Journal of Intellectual Property, Information Technology and E-Commerce Law 146

${ }^{61}$ Apple Computer Incorporated v Design Registry [2002] ECDR 19 (Chancery Division)

62 "It is important to appreciate that I am concerned only with icons which appear on a machine into which they are inherently built ... They not only form part of the machine which the public buy and discover once they get the machine home and switch it on; in practice, the icons are likely to be shown in shops and in advertisements. The design icon is an important part of the appearance of the article which people buy. Manufacturers of operating systems to be installed on computers, as is common knowledge, proclaim that their icons are attractive" per Jacob J

${ }^{63}$ For a perspective on the protection of CAD files under copyright law, see, Mendis D., Clone Wars': Episode II The Next Generation - The Copyright Implications relating to 3D Printing and ComputerAided Design (CAD) Files [2014] 6(2) Law, Innovation and Technology, pp. 265-281

64 See British Leyland Motor Corporation Ltd v Armstrong Patents Co. Ltd [1986] 2 WLR 400; [1986] AC 577 (House of Lords) (a design of exhaust pipes was protected by copyright as a drawing); Autospin (Oil Seals) Ltd v Beehive Spinning (A Firm) [1995] RPC 683 (Chancery Division) (the court 
could rely on. However, this is a cumbersome solution for designers, particularly in undermining the registered design system. Currently, the owner of a design enjoys absolute protection, without the need for proof of such copying.

In addressing this issue, Malaquias ${ }^{65}$ suggests a potential resolution, drawn from section 226 of CDPA 1988, by recommending the recognition of 'blueprints' as a protectable subject in design law as discussed below.

\subsection{The Legal Status of a CAD File under UK Unregistered Design Rights}

An unregistered design in the UK, following the introduction of the Intellectual Property Act $2014^{66}$, is now defined as the shape or configuration of the whole or part of an article, irrespective of whether it is internal or external. ${ }^{67}$ There is no statutory provision that limits the nature of an article to being industrially manufactured or handcrafted as with the Community registered and unregistered design rights as well as UK's registered right. Therefore, an article could, in theory, be more widely interpreted to encompass even a digital item. Nevertheless, it is worth noting Hacon J's assumption that the definition of a design, including the meaning of an article, could, in future, be construed as close as possible to that in the Community Design Regulation for policy reasons of consistency. ${ }^{68}$

In similar terms to the rest of design rights, there is no exact mentioning in UK UDR that a CAD file can be included within the scope of a design. However, there is a provision in relation to infringement of UK UDR that reads as follows:

\section{Primary infringement of design right}

(1) The owner of design right in a design has the exclusive right to reproduce the design for commercial purposes -

(a) by making articles to that design, or

(b) by making a design document recording that design for the purpose of enabling such articles to be made

\footnotetext{
held that a design of a three-dimensional article can be protected by copyright as a literary work if it is in the form of a data file)

${ }^{65}$ Malaquias P., Consumer 3D Printing: Is the UK Copyright and Design Law framework fit for purpose? (2016) 6 Queen Mary Journal of Intellectual Property 321

${ }^{66}$ Intellectual Property Act 2014, s 1(1)

${ }^{67}$ CDPA 1988, s 213(2)

${ }^{68}$ DKH Retail Ltd v H. Young (Operations) Ltd [2014] EWHC 4034 (IPEC); [2016] ECDR 9, [14] - [16]
} 
As can be seen above, UK UDR explicitly defines 'a design document', as being any record of a design, whether in the form of a drawing, a written description, a photograph, data stored in a computer or otherwise. ${ }^{69}$ Accordingly it could be submitted that a CAD file could fit within the definition of a design document, since it is essentially a computer file or data comprising the record of a three-dimensional object. If so, can a CAD file be infringed and under what circumstances would that happen? The section below explores these questions.

\subsection{Design Rights and Infringement Through 3D Printing}

One of the greatest concerns about 3D printing in the context of design rights infringement is that it could facilitate infringement through reproduction and dissemination of CAD files, akin to past issues relating to copyright from the entertainment industry. ${ }^{70}$ Up until now, designs have been secluded from the issues in a digital world, ${ }^{71}$ as it has not been possible for the average consumer to manufacture products for commercial purposes. ${ }^{72}$ Whilst Mendis and Secchi in their commissioned Report for the UK Intellectual Property Office (UKIPO) revealed that the activity on the sharing of CAD files on major online 3D printing platforms have been exponentially increasing since 2008, Reeves and Mendis also confirmed that infringement through design remained relatively low. ${ }^{73}$ This sentiment was also echoed in the commissioned report for the European Commission on industrial design by Dumotier et al who established, that the use of 3D printing by individuals to produce and reproduced designs in their homes is still very limited. ${ }^{74}$ For this reason, "copying of products bearing protected designs has not yet become a significant issue. Rather, the concern is based on the anticipated impact of such copying". ${ }^{75}$ For example, what will happen when individuals with 3D printers in their homes, have the capability to make a copy of a product bearing the design for their private use? Given the growing popularity of online 3D printing platforms, ${ }^{76}$ it is reasonable to anticipate that it may become a real issue.

\footnotetext{
69 CDPA 1988, s 263(1)

${ }^{70}$ Mendis D., "The Clone Wars": episode 1 - The Rise of 3D Printing and its Implications for Intellectual Property Law - Learning Lessons from the Past?' [2013] European Intellectual Property Review 155

${ }^{71}$ Bently L. and Sherman B., Intellectual Property Law (4th edn, Oxford University Press 2014)

72 Daly A., Socio-Legal Aspects of the 3D Printing Revolution (Macmillan Publishers 2016)

${ }^{73}$ Mendis D. and Secchi D., A Legal and Empirical Study of 3D Printing Online Platforms and an Analysis of User Behaviour (London: UK Intellectual Property Office; 2015); and Reeves P. and Mendis D., The Current Status and Impact of 3D Printing Within the Industrial Sector: An Analysis of Six Case Studies (Intellectual Property Office, 2015), pp. 21-22. For all reports, see, https://www.gov.uk/government/publications/3d-printing-research-reports

${ }^{74}$ Dumotier J., et at., Legal Review on Industrial Design Protection in Europe (MARKT2014/083/D)

(European Commission; 2016)

75 lbid, p. 131

${ }^{76}$ Reeves P. and Mendis D., The Current Status and Impact of 3D Printing Within the Industrial Sector: An Analysis of Six Case Studies (Intellectual Property Office, 2015). The authors suggested that $3 \mathrm{D}$ printing technology is yet immature to be a real concern to Intellectual Property rights holders
} 
At present, the registered proprietor of a community or UK registered design enjoys the exclusive right to use their design. ${ }^{77}$ The meaning of use of the design is described as the making, offering, putting on the market, importing, exporting or using of a product in which the design is incorporated or to which it is applied'78; or 'stocking such a product for those purposes'79. Performing any of the aforementioned acts without the consent of the registered proprietor could infringe the right in a registered design ${ }^{80}$, and the registered proprietor could claim remedy, such as damages or injunctions, against the infringer ${ }^{81}$.

As with registered design rights, the Community unregistered design right provides the right holders with the exclusive right to use unregistered designs, such as making or offering a product in which a design is incorporated or to which a design is applied. ${ }^{82}$ Notwithstanding that, the right holders of unregistered designs could only preclude the use of the unregistered designs by others insofar as such use is driven by copying of the protected unregistered designs. ${ }^{83}$

The owner of a UK unregistered design right, has the exclusive right to reproduce the design for commercial purposes in a way to make articles to that design or to make a design document in which the design is recorded to enable such articles to be made. ${ }^{84}$ Reproducing the design to make articles to the design is construed as meaning that copying of the design in order to produce articles either to the exact design or to the substantial part of the design ${ }^{85}$, and the reproduction could be either direct or indirect ${ }^{86}$. Without legitimate grounds, such as the consent or licence of the rights holder, a person who performs any of the acts exclusively permitted for the rights holder or authorises others to do those acts, infringes the unregistered design right. ${ }^{87}$ Over and above, importing an article into the UK for commercial purposes; possessing an article for commercial purposes; or selling, letting for hire, offering, exposing for sale or hire an article in the course of a business could constitute secondary infringement,

for another decade. But they still emphasised that there were some indications of potential intellectual property infringement on online $3 \mathrm{D}$ printing platforms

77 RDA 1949, s 7(1)

${ }^{78}$ RDA 1949, s 7(2)(a)

${ }^{79}$ RDA 1949, s 7(2)(b)

80 RDA 1949, s $7 A(1)$

${ }^{81}$ RDA 1949, s 24A(1) \& (2)

${ }^{82}$ Council Regulation (EC) No. 6/2002 of 12 December 2001 on Community designs [2002] OJ L3/1, Art 19(2)

83 ibid

${ }^{84}$ CDPA 1988, s 226(1)

${ }^{85}$ CDPA 1988, s 226(2)

${ }^{86}$ CDPA 1988, s 226(4)

87 CDPA 1988, s 226(3) 
provided that a person who does the above-mentioned acts knows that the article was an infringing article or it is reasonable to believe that the person knows that the article was an infringing article. ${ }^{88}$

In view of these rights available to proprietors of design rights, printing an item in which the appearance is protected by registered design right is likely to infringe the registered design right. However, can the making of a CAD file in which the protected design is stored, also constitute infringement? This is rather a grey area since, on the one hand, it might be argued that making a CAD file does not amount to infringement, in the sense that making a CAD file is neither an industrial nor a handcrafted item that is prohibited by virtue of section $7(2)$ of the RDA 1949. On the other hand, where portraying an image of a product in which a registered design right subsists was held to amount to use of the design, thereby constituting infringement, it could also be argued that making a CAD file infringes a design right. ${ }^{89}$ However, there is no case law in the UK which is directly concerned with how broadly 'using of a design' is interpreted, so clear guidelines are required for legal certainty in the UK.

Furthermore, it can also be questioned if sharing a CAD file of a product in which a registered design subsists could be infringing within the ambit of the RDA 1949. An interpretation of RDA 1949 , reveals that sharing a CAD file is unlikely to infringe the right in the registered design since it is unrelated to making or using of a product to which the registered design is applied or in which it is incorporated. Unlike UK unregistered design law where indirect infringement is prohibited ${ }^{90}$, there is no statutory protection against indirect or contributory infringing acts; accordingly, although sharing a CAD file could contribute to design rights infringement by enabling the public to do any aforementioned prohibited acts in section 7 of the RDA 1949, it is unlikely that it constitutes infringement. Nonetheless, it is still possible that such contributory acts could be prevented by the established case law, such as the law of joint tortfeasorship insofar as the acts could meet the requirements. ${ }^{91}$

However, some exceptions might be applicable with regards the design rights discussed above. Most significantly, when an infringing use of a design is only performed privately without resorting to commercial purposes ${ }^{92}$, the right in a registered design or unregistered

\footnotetext{
${ }^{88}$ CDPA 1988, s 227

${ }^{89}$ Case I ZR 56/09 Deutsche Bahn v Fraunhofer-Gesellschaft [2012] GRUR 12/2011

(Bundesgerichtshof, 7 April 2011) 1117 in Stone D., European Union Design Law: A Practitioners'

Guide (2nd edn, Oxford University Press 2016) 470

${ }^{90}$ CDPA 1988, s 227

91 L'Oréal SA v EBay International AG [2009] EWHC 1094; [2009] RPC 21, [343] - [358]

92 RDA 1949, s 7A(2)(a); CDPA 1988, s 244A(a)
} 
design is not infringed. Additionally, reproduction of a design is allowed if it is done for educational purposes ${ }^{93}$ on condition that it does not unduly prejudice the normal exploitation of the design and the source is acknowledged ${ }^{94}$. The section below questions whether any such exceptions can be applied to the 3D printing scenario.

\subsection{Potential Exceptions for Users of 3D Printing Technologies}

As established above, it seems somewhat uncertain if making or sharing a CAD file could constitute infringement. On assumption that it could infringe, such acts could be still exempted from liability if they are done privately and non-commercially. ${ }^{95}$ For instance, making a CAD file at home by way of 3D scanning an existing product protected by design rights without any commercial rewards such as a commissioning fees will not infringe the design. On the contrary, it is rather unclear whether sharing a CAD file could also be permitted under this exception since determining whether the nature of sharing is commercial or non-commercial might be extremely ambiguous. Moreover, 3D scanning of an existing product protected by design right to create a CAD file could also be allowed at universities or schools for educational purposes. ${ }^{96}$

Therefore, according to the current exceptions, individuals would have a strong claim that their actions are private and for non-commercial purposes. At the same time, an individual who 3D prints several copies for sale or distribution cannot rely on the exception as his use will no longer been seen as "non-commercial". 97

Uncertainty in the interpretation of infringement provisions and the exceptions that exempts most liability with non-commercial use of 3D printing in the domestic sector appear to create some structural bias against design rights holders. ${ }^{98}$ Though 3D printing may not expose

\footnotetext{
${ }^{93}$ RDA 1949, s 7A(2)(c); CDPA 1988, s 244C(c)

${ }^{94}$ RDA 1949, s 7A(3); CDPA 1988, s 244C(c)

${ }^{95}$ Making a three-dimensional product out of a CAD file via 3D printers is also exempted from liability if done at home for non-commercial purposes

${ }^{96}$ For example, a re-creation of Henry VIII Crown, in the form of a CAD file, was made available for download and 3D printing for non-commercial purposes by the Historic Royal Palaces in 2014. See https://www.thingiverse.com/thing:335960

${ }^{97}$ Dumotier J., et at., Legal Review on Industrial Design Protection in Europe (MARKT2014/083/D) (European Commission; 2016); See also, Economic Review of Industrial Design in Europe (MARKT2013/064/D2/ST/OP) (Europe Economics; 2015), p. 135

98 Legal review on industrial design protection in Europe: under the contract with the Directorate General Internal Market, Industry, Entrepreneurship and SMEs (European Commission, 2016) (this structural problem could be yet hypothetical since, as the researchers emphasised, without more research on the impacts of $3 \mathrm{D}$ printing in the industries and in the domestic sector it is too early to decide to employ a new policy or law)
} 
imminent concerns at present, ${ }^{99}$ the supply of products in digital formats, will mean that there will be a shift within corporations from their role of manufacturers to service providers. ${ }^{100}$ In preparation for such a change, it is desperately required that provisions of design rights infringement and exceptions are reviewed, whilst the secondary infringement through intermediary liability should equally be evaluated.

\section{Enforcing Design Rights for 3D Printing: Recommendations for the Future}

As with all intellectual property rights, a design right is only as effective as the ability of the holder to enforce it. As such, enforcement is clearly an area which needs attention, particularly in view of new technologies such as 3D printing. Anti-Copying in Design (ACID) - one of the interest groups representing design rights holders - has consistently showed great concerns about the emergence of 3D printing. This is because 3D printing could be utilised for organised thefts of design due to its mobility and handiness. ${ }^{101}$ In addition, dealing with CAD files, including reproduction and dissemination of a protected design, could become uncontrollable by design rights holders with particular regards to CRDR, CUDR and UK RDR, and thus unenforceable in the current landscape of design law where the protection of a CAD file is uncertain.

Against this background, it is worth noting that intentional copying of a registered design in the UK, carried out in the course of a business ${ }^{102}$ was recently criminalised under registered design rights, by virtue of Intellectual Property Act $2014 .{ }^{103}$ This is most certainly a firm step forward in enforcing design rights. However, the effect of this new provision is that copying or circulating CAD files for non-commercial purposes does not fall within the ambit of this provision ${ }^{104}$ which continues to leave open the question of dealing with end-users and online platforms.

\footnotetext{
${ }^{99}$ Reeves P. and Mendis D., The Current Status and Impact of 3D Printing Within the Industrial Sector: An Analysis of Six Case Studies (Intellectual Property Office, 2015)

${ }^{100}$ Kietzmann J., Leyland Pitt and Pierre Berthon, Disruptions, Decisions, and Destinations: Enter the Age of 3-D Printing and Additive Manufacturing (2015) 58 Business Horizons 209

${ }_{101}$ ACID <www.acid.uk.com/about/> accessed 28 February 2018

102 RDA 1949, s 35ZA

103 Intellectual Property Act 2014, s13

${ }^{104}$ For how this provision has been applied, see IP Crime Report 2015/16 (UKIPO, 2016) (a large number of design rights holders participating in the survey indicated that either that the level of infringement had stayed the same as before or that they did not know if the new provision had helped in any ways. From these responses, it might be assumed that the provision has not exerted any remarkable influence on deterring design rights infringement. For one possible reason behind it, registered design system in the UK is underutilised since many designers rely on unregistered design rights in preference to registered design rights)
} 
Dumotier et al, in their 2016 report, point out that the two main areas for enforcement against unauthorised 3D printing are in fact "the end-user and the intermediaries involved in facilitating the download and eventual reproduction by the end-user". ${ }^{105}$ However, the report goes on to recognise the fact that it can be challenging and costly to enforce rights against end-users, due to the decentralised nature of the activity. As such, the report suggests that "pursuing intermediaries, particularly online hosting sites, may provide a more streamlined enforcement option for rights holders", ${ }^{106}$ through the mechanism of injunctions although there are not yet any examples of such injunctions being granted in respect of 3D printing. With online platforms such as Thingiverse, Shapeways having already experienced the issuance of court order requesting the takedown of infringing files, it may become more relevant to focus on intermediary parties which are positioned upstream of the ultimate domestic printing. ${ }^{107}$

If the focus on intermediaries is the way forward, then how can this aim be achieved? Dumotier et al and Mendis et al, in their 2016 and 2015 reports, respectively, provide a number of suggestions and recommendations in looking ahead to the future, as set out below.

Adopting a patent-like indirect design infringement: Unlike design law, European patent law provides against indirect third party patent infringement. ${ }^{108}$ These provisions act as a trigger to prevent anyone uploading a 3D printing file onto a website, where the uploaded file has the potential to infringe patent or design laws, in the final product. Accordingly, adopting such provisions against indirect design infringement "would facilitate enforcement as it allows enforcing design rights against the distributor of a 3D printer file as the 'spider in the web"'.109

Adopting a copyright-like direct design infringement by authorisation: Another solution for enforcing design rights in the 3D printing landscape, can be drawn from copyright law through the means of introducing a provision which sanctions authorisation of design infringements ${ }^{110}$. Such a provision is available under the CDPA $1988^{111}$ and will provide a means for capturing primary infringers. As Dumotier et al state, "this has the advantage that neither actual nor constructive knowledge would be required for a positive finding of

\footnotetext{
${ }^{105}$ Dumotier J., et at., Legal Review on Industrial Design Protection in Europe (MARKT2014/083/D) (European Commission; 2016); See also, Economic Review of Industrial Design in Europe (MARKT2013/064/D2/ST/OP) (Europe Economics; 2015), p. 131

106 ibid

107 Mendis D. and Secchi D., A Legal and Empirical Study of 3D Printing Online Platforms and an Analysis of User Behaviour (London: UK Intellectual Property Office; 2015), pp. 43-44

108 Section 60 (2) UK Patents Act 1977, stemming from the Community Patent Convention 1975

109 See, Dumotier J., et al, n. 46 p. 132

110 ibid

111 Section 16 (2) Copyright, Designs and Patent Act 1988
} 
infringement as would be necessary in relation to secondary liability". ${ }^{112}$

Encouraging creators to licence their work through an opt-out approach: Intermediaries encourage the use of licences such as Creative Commons, Commons Attribution and GNU Public Licence when using 3D printing online platforms. However, $65 \%$ of users engaged in the activities of 3D printing online platforms do not license their work, leaving their creations vulnerable and open to infringement whilst losing the ability to claim authorship. ${ }^{113}$ Although a lack of licence attribution may be linked to a user's ignorance or misunderstanding of the intricacies associated with each licence, it may sometimes be done intentionally as the file has been uploaded in breach of intellectual property laws. To overcome such issues, online platforms can assign the most appropriate licence (e.g. GNU, Creative Commons) as a default with 'opt-out' as an option, which has the benefit of protecting rights holders whilst it could act as a deterrent for potential infringers. ${ }^{114}$ It will also strengthen the online platforms' position of working within the parameters of the law.

Limiting the private use defence: A final solution would be to limit the private use defence by adopting the three-step language as provided under the Trade Related Aspects of Intellectual Property (TRIPs) Agreement. ${ }^{115}$ This approach would permit sufficient flexibility to allow a balance to be struck between protecting the interests of the rights holders whilst paving the way for innovation. As Dumotier et al, argue, "although the introduction of additional criteria such as "normal exploitation" may create confusion, this may be easily resolved as there is already some guiding case law on this from the WTO Dispute Settlement Body". ${ }^{116}$

It is, however, important to recognise that this technology is developing rapidly. Therefore, "the strategy of targeting intermediaries could become obsolete if users have access to technology which enables them to make a scan of the object in their own home, and then print". ${ }^{117}$ With the future of $3 \mathrm{D}$ printing, pointing in this direction, it would be useful to clarify what constitutes design infringement by including the creation of a design document as an

\footnotetext{
112 See, Dumotier J., et al, n. 46 p. 132

${ }_{113}$ Mendis D and Secchi D., n. 73 pp. 43-44

114 ibid

115 The proviso under Art. 26, TRIPS Agreement reads as follows: "provided that such acts do not unreasonably conflict with the normal exploitation of the design, and does not unreasonably prejudice the legitimate interests of the owner of the protected design owner, taking account of the legitimate interests of third parties."

${ }^{116}$ See, Dumotier J., et al, n. 46 p. 132. For example, see, Dispute Settlement Board decision WT/DS114 concerning the interpretation of the 3-step test as provided under Article 30 of TRIPS. The wording is similar to the wording in Article 5(5) InfoSoc Directive and it is useful to note that the CJEU has applied the three step test in copyright cases - see Football Association Premier League Ltd and Others v QC Leisure and Others, Case C-403/08; Technische Universität Darmstadt v Eugen Ulmer $K G$, Case C-117/13
}

117 See, Dumotier J., et al, n. 46 p. 133 
infringing use as discussed above. ${ }^{118}$

\section{Conclusion}

The issue of $3 \mathrm{D}$ printing will become more acute, as the technology improves and the printers are able to reproduce perfect substitutes of the original design. At the same time, it is becoming increasingly clear that consumers will claim the right to use 3D machines, and claim private use privileges under fair dealing, or private, non- commercial use defences. ${ }^{119}$ These entitlements should be balanced against the rights of intellectual property owners. As mentioned above, the current sentiment appears to be that 3D printing is a technology that will do for physical objects what MP3 files did for music and film. ${ }^{120}$

In considering such issues, this chapter explored the implications of 3D printing for design rights in the UK. The chapter argued that the current design law might not be inclusive and clear enough to embrace the issues that could derive from use of CAD files, bearing in mind that $3 \mathrm{D}$ printing has great potential to disrupt the landscape of design rights protection.

The protection of a CAD file embodying a protectable design should be clearer. It seems likely that the protection of a CAD file will fall within the ambit of copyright works. However, it is not desirable that design rights holders are compelled to rely on copyright law at all times rather than design rights to protect their designs. Thus, reviewing the law and introducing clear guidelines for dealings with CAD files is necessary for both rights holders and users.

Furthermore, infringement and exceptions provided in design law may require some reconsideration, in terms of striking the balance between the conflicting interests amongst design rights holders and users. Prior to the emergence of $3 \mathrm{D}$ printing, it was somewhat unthinkable that functional three-dimensional objects could be fabricated at home, and thus the private and non-commercial exception might have not been a serious issue. However, home $3 \mathrm{D}$ printing has the potential to change the landscape of the future designer. It is,

\footnotetext{
${ }^{118}$ A template for such a provision could be Section 226 (1)(b) CDPA 1988 which extends primary design infringement to "making a design document recording the design for the purpose of enabling such articles to be made". The definition of a design document is provided within Section 263 CDPA 1988 and states that "design document" means any record of a design, whether in the form of a drawing, a written description, a photograph, data stored in a computer or otherwise." This definition encompasses CAD created for the purposes of 3D printing

119 Dumotier J et al, n. 46 p. 132

${ }^{120}$ Mendis D., "The Clone Wars": episode 1 - The Rise of 3D Printing and its Implications for Intellectual Property Law - Learning Lessons from the Past?' [2013] European Intellectual Property Review 155, pp. 154-155
} 
therefore, necessary to address the rights of the user and consider policy recommendations for the future.

Last but not least, revising the enforcement regime in design law is crucial before 3D printing becomes more pervasive. In particular, there should be measures adopted to take control of the dissemination of CAD files, so as to deter illegitimate online reproduction of protected designs. To that end, it might be necessary to consider adding a set of new digital rights that address management, production and infringement issues arising from 3D printing in the design landscape. ${ }^{121}$ In response, this chapter outlined potential solutions drawn from copyright and patent laws which could be reflected upon in the context of intermediaries, rights holders and end users. Ultimately, in looking ahead to the future of design laws, it is clear that a fine balance will have to be struck between protecting intellectual property rights and ensuring that designers retain incentives to invest in the development of new designs. The first step in this process will be to clarify specific areas of uncertainty in current European and national laws. ${ }^{122}$

${ }^{121}$ Economic Review of Industrial Design in Europe (MARKT2013/064/D2/ST/OP) (Europe Economics; 2015), p. 8

122 See also, ibid, p. 133 